\title{
Vasco de Magalhães-Vilhena [, Maurice CORNFORTH] E A CRÍTICA MARXISTA AO Pragmatismo
}

\author{
Paulo Antunes ${ }^{1}$ \\ (Universidade de Lisboa)
}

\begin{abstract}
É no processo da atividade prática, sobre as bases das necessidades materiais da vida da sociedade (não na prática concebida de um modo limitado, reduzida à experiência e ao experimento, não na prática concebida no espírito do subjetivismo dos pragmatistas e instrumentalistas) que não só se têm aperfeiçoado historicamente os próprios órgãos dos sentidos humanos e se os tem prolongado pela técnica, como se desenvolve o pensamento abstrato com base na linguagem e que, instância decisória, se verifica em que dose e até que ponto é ou pode ele ser, dentro de quadros sociais históricos determinados, fidedigno e verdadeiro. Vasco de Magalhães-Vilhena, 1964.
\end{abstract}

\section{$\S 1$. Notas preambulares: em memória de Vasco de Magalhães-Vilhena}

Antes de começar, gostava de cumprimentar todos os presentes dizendo que é com enorme satisfação que me encontro aqui a prestar homenagem a Vasco de Magalhães-Vilhena (1916-1993) que já só me chegou através dos seus escritos, o que porventura muito honrará a quem fez do

\footnotetext{
${ }^{1}$ pauloantunes@campus.ul.pt

Philosophica, 49, Lisboa, 2017, pp. 65-78.
} 
pensamento e da escrita parte essencial da sua vida ${ }^{2}$.

Avancemos que o tempo é escasso para delongas.

A comunicação que vos apresento, mais do que tomar como objeto a bibliografia e/ou biografia do homenageado ou apresentar sucintamente um tema ou temas que o cativaram, pretende, antes, servir-se de uma ou outra referência episódica dos seus textos. Para o caso, a comunicação pretende servir-se das referências que remetem, como o título anuncia, para a crítica marxista ao Pragmatismo. Crítica que Magalhães-Vilhena não terá desenvolvido, porém, assinalou.

Maurice Cornforth (1909-1980) é o autor para o qual o nosso homenageado remete o essencial da crítica ao Pragmatismo, ainda que mais frequentemente a propósito da crítica ao positivismo desenvolvida por este autor britânico ${ }^{3}$. Cornforth é quase sempre referido de fugida ou em nota de rodapé ${ }^{4}$, daí, o caráter episódico das referências e o parentético acom-

2 Cabe ainda assinalar que o seu nome ressoa como exemplo de militância política e filosófica. Para um devido reconhecimento biográfico do homenageado veja-se, por exemplo: António Melo, "Magalhães-Vilhena, esboço de um retrato", in Eduardo Chitas; Hernâni A. Resende (coord.), Filosofia. História. Conhecimento. Homenagem a Vasco de Magalhães-Vilhena, Lisboa: Editorial Caminho, 1990, pp. 301-317, uma entrevista ao próprio, Maria Ivone de Ornelas Andrade (Entrevista conduzida por), "Vasco de Magalhães-Vilhena, um pensador marxista", in Eduardo Chitas; Hernâni A. Resende (coord.). Filosofia. História. Conhecimento. Homenagem a Vasco de Magalhães-Vilhena, Lisboa: Editorial Caminho, 1990, pp. 327-340, e uma recente evocação, José Paulo Netto, "Magalhães-Vilhena: um marxista erudito - e não só", publicado no Blog da Boitempo, 2016. Consulta a 1 de maio de $2016 \mathrm{em}$ : http://blogdaboitempo.com.br/2016/01/19/ magalhaes-vilhena-um-marxista-erudito-e-nao-so/.

3 Cf. Maurice Cornforth, Science Versus Idealism. In Defense of Philosophy Against Positivism and Pragmatism, London: Lawrence \& Wishart, 1955. Sempre que remete para Cornforth, Magalhães-Vilhena destaca Science Versus Idealism. In Defense of Philosophy Against Positivism and Pragmatism de 1955. Esta obra é resultado da compilação de outras duas, cf. Maurice Cornforth, Science Versus Idealism. An Examination of "Pure Empiricism" and Modern Logic, London: Lawrence \& Wishart, 1946; e In Defense of Philosophy. Against Positivism and Pragmatism, London: Lawrence \& Wishart, 1950. A respetiva obra pode ser encontrada na Biblioteca Magalhães-Vilhena, recentemente doada (2015) pelo Partido Comunista Português à Biblioteca da Faculdade de Letras da Universidade de Lisboa (na cota do homenageado: prat.7 c/c 46) - esta biblioteca contém mais de dez mil entradas colecionadas ao longo de uma vida dedicada à investigação. Mas é em In Defense of Philosophy. Against Positivism and Pragmatism de 1950 em que nos vamos basear, visto conter o fundamental da crítica ao Pragmatismo (cf. Cornforth, In Defense of Philosophy, c. 7, pp. 157-216).

4 Por exemplo, cf. Vasco de Magalhães-Vilhena, António Sérgio. O Idealismo Crítico e a Crise da Ideologia Burguesa, Lisboa: Seara Nova, 1964, p. 119; António Sérgio - O Idealismo Crítico: Génese e Estrutura. Raizes Gnoseológicas e Sociais. Estudo de História Social das Ideias, edição, prefácio e notas: Hernâni Resende, Lisboa: Edições Colibri, 2013, pp. 488-489. 
panhamento no título (que nada mais terá de misterioso).

Estas referências episódicas aparecem aqui e ali ao longo da reflexão do autor português em torno de António Sérgio (1883-1969), em torno do seu idealismo, mas especialmente do seu compromisso com o racionalis$\mathrm{mo}^{5}$. É, assim, do ponto de vista de um racionalismo, perspetivado materialisticamente, que Cornforth aparece.

Por conseguinte, o destaque que aqui é dado ao autor britânico não se apresenta como um capricho de "micrologia" filosófica e encontra inclusive uma discreta autorização pela parte do próprio Magalhães-Vilhena. Atente-se na seguinte passagem:

Dos livros de [Reginald] Kapp (Science versus Materialism [1940]) e de Cornforth (Science versus Idealism) - citados com anuência o primeiro por Sérgio e o segundo por nós - o título que traduz o sentido mesmo da progressão da ciência é, sem contestação, o segundo ${ }^{6}$.

Magalhães-Vilhena dá-nos, assim, a sua anuência e a partir daqui será desenvolvido o resto da comunicação ${ }^{7}$.

5 "Como definir a feição caraterística de Sérgio? A sua doutrina é, em primeiro de tudo, um racionalismo. E este, tal como ele o concebe, numa perspetiva idealista [...].", sublinhado do autor, Magalhães-Vilhena, António Sérgio. O Idealismo Crítico e a Crise da Ideologia Burguesa, p. 10.

6 Magalhães-Vilhena, António Sérgio - O Idealismo Crítico: Génese e Estrutura, p. 185. Cf. Reginald O. Kapp, Science versus Materialism, London: Methuen \& Co. Ltd., 1940.

7 Faço ainda um alerta, Cornforth tomará a palavra, embora seja ponto assente, este autor não foi o único que, de um ponto de vista marxista, criticou o Pragmatismo (por exemplo, cf. Harry K. Wells, Pragmatism: Philosophy of Imperialism, London: Lawrence \& Wishart, Ltd. 1954; George Novack, Pragmatism versus Marxism: An Appraisal of John Dewey's Philosophy, New York: Pathfinder Press, Inc., 1975), porém, foi o único que logrou a anuência declarada. Não obstante o anunciado, Vladimir Lénine (1870-1924), mormente por intermédio do seu Materialismo e Empiriocriticismo (1908), servirá de apoio à subsequente exposição, uma vez que inspirou tanto o nosso homenageado como Cornforth. Deste modo, privilegiam-se pensadores marxistas, mais do que os próprios Karl Marx (1818-1883) e Friedrich Engels (1820-1895), visto que os dois fundadores apenas escassamente conviveram de perto com o Pragmatismo (último quartel do séc. XIX). George Novack (1905-1992) também servirá de apoio visto ter sido um dos autores que mais exaustivamente analisou o Pragmatismo de um ponto de vista marxista. 


\section{§ 2. A máxima do Pragmatismo, algumas repercussões e a crítica marxista}

Para o efeito proposto, comecemos pela máxima do Pragmatismo. Comecemos assim, apesar de não ser uma teoria fácil de circunscrever, uma vez que existem quase tantos "pragmatismos" como autores pragmatistas $^{8}$, todavia, quase todos partiram mais ou menos deliberadamente desta máxima (quer a referindo diretamente ou não):

Considerando quais os efeitos que concebivelmente podem ter implicações práticas, nós concebemos o objeto que a nossa conceção tem. Então, a nossa conceção destes efeitos é o todo da nossa conceção do objeto ${ }^{9}$.

O que quer dizer que concebemos o objeto a partir do momento em que concebemos "praticamente" os seus efeitos, na medida em que estes venham a corresponder a uma conceção prévia do próprio objeto. Esta é uma conceção a aplicar em determinada experiência, e na medida em que esta resulte inteiramente, obtém-se aquilo que o objeto é.

Esta é a prática do Pragmatismo: não é mais do que uma experiência subjetiva. Tudo o que o sujeito pode conhecer são as sensações de onde resulte a confirmação do pré-concebido, a prática não vai além do que é "imediatamente dado", para o caso, imediatamente correspondente.

O Pragmatismo ao pretender superar a "simples contemplação", exortando a uma tal prática, coloca ao concebimento de cada sujeito a incumbência de uma (pré-)definição de "regras para a ação" (rules for action $\left.{ }^{10}\right)$.

8 Por exemplo, cf. Arthur Lovejoy, "The Thirteen Pragmatisms. I", The Journal of Philosophy, Psychology and Scientific Methods, vol. V, no. 1, January 2, 1908, pp. 5-12; "The Thirteen Pragmatisms. II", The Journal of Philosophy, Psychology and Scientific Methods, vol. V, no. 2, January 16, 1908, pp. 29-39.

9 "Consider what effects that might conceivably have practical bearings we conceive the object of our conception to have. Then, our conception of these effects is the whole of our conception of the object.", sublinhados nossos, Charles Sanders Peirce, "How to Make Our Ideas Clear". Philosophical Writings of Peirce Sel. and ed. Justus Buchler, New York: Dover Publications, 1955, p. 31. O Pragmatismo teve como primeira formulação um texto de 1878 - "How to make our ideais clear" - de Charles Sanders Peirce (1839-1914), onde se encontra a passagem citada, mas foi denominado "Pragmatismo" pela primeira vez apenas em 1907 em Pragmatism: A New Name for Some Old Ways of Thinking de William James (1842-1910), compilação de algumas das suas conferências. Apesar de devidamente cotejado com algumas obras dos principais fundadores do Pragmatismo, o essencial do que aqui se entende por Pragmatismo é resultado da análise da máxima apresentada e do seu confronto com a interpretação crítica de Cornforth a alguns dos principais "pragmatismos", principalmente ao correspondente a John Dewey (1859-1952). Cf. Cornforth, In Defense of Philosophy, pp. 157-216.

10 Cf. Peirce, "How to Make Our Ideas Clear", pp. 36-37; William James, Pragmatism: A 
É no que "resulta" onde se encontra a ênfase do Pragmatismo, no "sucesso" das nossas ações. Pois de pouco servirá definir "regras" se não advir algum sucesso da sua aplicação. Um sucesso medido pelo que dos efeitos da experiência se consiga "casar" com o acumulado de outras experiências passadas, ou seja, é a partir dessas experiências que o sujeito concebe, procurando adequar a sua experiência a outras experiências anteriores ${ }^{11}$.

Todas as "leis" (ou regras) serão meramente postas pelo sujeito e não reflexos aproximados e generalizados do que é o desenvolvimento real natural e/ou social ${ }^{12}$. A ciência terá, com efeito, apenas valor prático, conforme as experiências "bem-sucedidas". Assim, parece existir um certo preconceito sobre o que é a ciência, resultando num alargamento, seguramente indevido, do que os pragmatistas julgam ser o método experimental, aos mais diversos momentos do real ${ }^{13}$.

new name for some old ways of thinking, New York: Longmans, Green, and Co., 1908, p. 46. Vejamos uma proposta para o funcionamento de tal "mecanismo": o pensamento responde a um estímulo (stimuli, por exemplo, cf. John Dewey, Essays in Experimental Logic, Chicago, Illinois: The University of Chicago Press, 1916, pp. 103-135 passim) e então pode aplicar as tais "regras para a ação". Trata-se de uma espécie de "intraorgânico" (intra-organic) estimulado por um "extraorgânico" (extra-organic), correlacionando-se (cf. Dewey, Essays in Experimental Logic, pp. 227-228). Deste modo, o conhecimento não passa de uma tentativa para "garantir" maior "assertibilidade" (assertibility), ou seja, tudo o que importa serão as experiências a que as ideias se submetem, e, nessa prática, se a "bota bater com a perdigota", então temos tudo o que o objeto é, todo o acerto-sucesso necessário. Em âmbito pragmatista, nem poderia ser de outro modo, uma vez que para "além" da experiência, tudo o que existe é, na melhor das hipóteses, uma "existência bruta" (brute existence), indeterminada (cf. Dewey, Essays in Experimental Logic, pp. 362-363). Porquanto, é por meio das "regras para a ação" que o indeterminado pode lograr determinação. Quer dizer, a categoria é lógica e não ontológica. Por exemplo, para o Pragmatismo a causalidade não é real, mas uma maneira do ser humano "arrumar" a realidade que na prática conhece. Cf. Cornforth, In Defense of Philosophy, p. 198.

11 Cf. James, Pragmatism, p. 64.

12 Cf. James, Pragmatism, p. 58.

13 '“[...] [a] 'verdade' nas nossas ideias e crenças significa a mesma coisa que significa em ciência. Significa, dizem eles [Dewey e F. C. S. Schiller (1864-1937)], nada mais do que isso, que as ideias (que são elas próprias não mais do que partes da nossa experiência) tornam-se verdadeiras apenas na medida em que elas nos ajudam a entrar numa relação satisfatória com outras partes da nossa experiência, resumi-las, e obter de entre elas, por atalhos concetuais em vez de seguir a sucessão interminável de fenómenos particulares."-“[...] 'truth' in our ideas and beliefs means the same thing that it means in science. It means, they say [Dewey and F. C. S. Schiller (1864-1937)], nothing but this, that ideas (which themselves are but parts of our experience) become true just in so far as they help us to get into satisfactory relation with other parts of our experience, to summarize them and get about among them by conceptual short-cuts instead of following the interminable succession of particular phenomena.", James, Pragmatism, p. 58. 
Posto isto, o Pragmatismo apresentará repercussões desde logo gnosiológicas, mas também ontológicas e políticas.

Das repercussões gnosiológicas - de facto, o seu primordial desiderato - podemos assinalar a experiência como fonte privilegiada de conhecimento, mas a experiência tal como já pudemos dar conta, acabando por remeter para uma perspetivação de equivalência entre sujeito e objeto. Isto é, sujeito e objeto serão co-dependentes, correlacionam-se em igual medida: há objeto porque o sujeito o concebe, mas tem de haver algum objeto para que da sua experiência resultem determinados efeitos ${ }^{14}$.

O Pragmatismo parece não passar de um subjetivismo ${ }^{15}$. Apesar dos pragmatistas não advogarem em causa da primazia nem do sujeito nem do objeto, deste em particular, acabam por colocar no sujeito - ao equivalê-los - a condição de possibilidade do objeto. Há objeto porque o experienciamos, desde que os efeitos da respetiva experiência resultem no que previamente se concebeu. É esta a única possibilidade de conhecimento.

Neste sentido, pouco interessa o estatuto (independente e exterior à consciência) do objeto. O Pragmatismo acaba por recusar toda a possibilidade de se conhecer alguma realidade objetiva, pois esta não estará ao alcance da experiência humana.

Mesmo recusando a famosa "coisa em si" kantiana, o Pragmatismo parece aceitar, ainda que não declaradamente, o mesmo preconceito kantiano: o que refere uma suposta incognoscibilidade da realidade objetiva, isto é, não se pode conhecer verdadeiramente o que é independente e exterior à experiência do sujeito (paradoxalmente, o que define a própria "coisa em si"!).

Por meio do seu subjetivismo, o Pragmatismo também se enquadra como irracionalista: não se pode conhecer qualquer objetividade real - o que seja independente e exterior à consciência - então, não pode haver conhecimento das "leis" que regem a natureza e a sociedade (é importante não confundir umas com as outras) $)^{16}$. Confirma-se, a ciência tem apenas "valor prático" subjetivo.

14 O Pragmatismo não pretende afirmar a primazia nem de sujeito nem de objeto. Assim, os pragmatistas julgam superar a cisão entre ambos, bem como a "coisa em si" (Ding an sich) kantiana. Por um lado, sujeito e objeto precisam um do outro e, por outro lado, na prática que leva um ao outro, a "coisa em si" parece perder o seu sentido desde que haja "resultados".

15 Reveja-se a presente epígrafe, Magalhães-Vilhena, António Sérgio. O Idealismo Crítico e a Crise da Ideologia Burguesa, pp. 49-50.

16 “A dificuldade principal e central em que o pragmatismo está envolvido pode ser expressa 
Daí, Cornforth assinala duas tradições com evidente peso no Pragmatismo (e que são provavelmente as mais relevadas pela crítica marxista):

a berkeliana, por intermédio do idealismo subjetivo e da consequente recusa de um conhecimento que dê conta da objetividade real (matéria) - visto que apenas o resultado de uma experiência (a sensação) pode ser real ${ }^{17}-$;

e, a kantiana, por intermédio (mais do que da assunção da incognoscibilidade da objetividade real e apesar da recusa da "coisa em si") do concebimento de "regras para a ação" com que o sujeito antecipa o objeto e assim arruma subjetivamente a indeterminação ${ }^{18}$.

de uma forma preliminar nos seguintes termos: É verdade que temos de formular ideias e teorias, não a fim de correlacionar os nossos dados dos sentidos, mas para informar a nossa conduta e para nos guiar em 'fazer a natureza de novo' e 'mudar as realidades existentes'. Mas conscientemente para mudar realidades supõe-se a existência de realidades para mudarmos, e um conhecimento das suas propriedades, interconexões e leis do movimento. Foi bem escrito - embora não por um pragmatista - que 'a liberdade é o conhecimento da necessidade'. Quer dizer, podemos conscientemente direcionar os nossos esforços para resultados pretendidos na proporção em que conhecemos as propriedades e as leis objetivas dos objetos e os processos com os quais temos de lidar. As nossas ideias de trabalho, para servir o seu propósito como 'regras para a ação', devem corresponder ao objeto real e às suas propriedades, e devem reproduzir ou 'copiar' as interconexões e as leis do mundo objetivo." - "The chief and central difficulty in which pragmatism is involved can be expressed in a preliminary way as follows: It is true that we need to formulate ideas and theories, not in order to correlate our sense-data, but to inform our conduct and to guide us in 'making nature over again' and 'changing existing realities'. But consciously to change realities supposes the existence of realities for us to change, and a knowledge of their properties, interconnections and laws of motion. It has been well written - though not by a pragmatist - that 'freedom is knowledge of necessity'. That is to say, we can consciously direct our efforts to intended results in proportion as we know the objective properties and laws of the objects and processes with which we have to deal. Our working ideas, to serve their purpose as 'rules of action', must be made to correspond to real object and their properties, and must reproduce or 'copy' the interconnections and laws the objective world.", Cornforth, In Defense of Philosophy, pp. 160-161.

17 Recorde-se a sentença de George Berkeley (1685-1753) presente em todos os manuais: "existir é ser percebido" (esse est percipi, cf. George Berkeley, Principles of Human Knowledge and Three Dialogues, Oxford University Press., 1996, I, 3, p. 25).

18 Para maior precisão, atente-se ao significado particular que a "indeterminação" apresenta em Immanuel Kant (1724-1804): "coisa em si”, existência de algo "além" da consciência, porém, sempre incognoscível. Mas, como já foi visto, não é desta maneira que é aceite pelos pragmatistas. Para Berkeley, e ainda mais para David Hume (1711-1776), ambos por antecipação à formulação kantiana, nem de uma "coisa em si" se poderia falar, pois isso será metafísica. É a estes dois autores que os pragmatistas mais se aproximam, no que a isto diz respeito. Pois, se na acusação de um "transcensus", Berkeley, Hume 
Segundo Cornforth, o Pragmatismo opera (embora mais particularmente com base em Dewey) um "twist" tipicamente kantiano ao berkelianismo (Dewey gives Berkeley's subjective idealism a typically Kantian twist ${ }^{19}$ ).

Quanto às repercussões ontológicas, talvez não sejam muito difíceis de prever, uma vez que já se terão feito antever no que até aqui foi exposto.

A objetividade real, a materialidade, é, portanto, secundarizada face a um condicionamento subjetivo. De acordo com Cornforth, tal é a confusão entre o objeto de conhecimento, que existe independentemente do sujeito que conhece, com aquilo que dele o sujeito consegue dar conta através da sua investigação ${ }^{20}$.

Se o objeto é tudo o que dele podemos conceber, o seu estatuto ontológico independente de um sujeito encontra-se definitivamente em risco. Ora, não há espaço para o ser sem sujeito. Esta será, podemos adiantar, uma das façanhas mais próprias de uma teoria que faça co-depender su-

e Kant concordam na sua incognoscibilidade, é na aceitação de uma "coisa em si" que o pensador alemão realmente difere dos outros dois (por exemplo, cf. Immanuel Kant, Kritik Der Reinen Vernunft, Hamburg: Verlag Von Felix Meiner, 1956, B XXV-XXVII). São os fenómenos que a "coisa em si" pode suscitar que podem ser "arrumados" pelo sujeito, o que já não acontece com os dois pensadores britânicos, mas um efeito semelhante, apesar de tudo, poderá ser encontrado nos pensadores pragmatistas.

19 Cornforth, In Defense of Philosophy, p. 193. Faltaria ainda cotejar a máxima pragmatista com Auguste Comte (1798-1857), algumas conceções de darwinismo, entre outras coisas. Faltaria também uma devida comparação com o idealista alemão Johann Gottlieb Fichte (1762-1814), lembremos a questão do "sujeito como condição de possibilidade" e atente-se na seguinte passagem: "[...] a atividade pura do eu que retorna a si próprio é, em relação a um possivel objeto, um esforço; e, com efeito, em conformidade com a demonstração acima [a que se refere ao pôr [Setzen]-se de um não-Eu por um Eu absoluto], um esforço infinito. Este esforço infinito é, até ao infinito, a condição de possibilidade de todo o objeto: sem esforço, não há objeto.” - “[...] die reine in sich selbst zurückgehende Thätigkeit des Ich ist in Beziehung auf ein mögliches Objekt ein Streben; und zwar, laut obigem Beweise, ein unendliches Streben, Dieses unendliche Streben ist in's unendliche hinaus die Bedingung der Möglichkeit alles Objekts: kein Streben, kein Objekt.”, sublinhados do autor, Johann Gottlieb Fichte, Grundlage der gesamten Wissenschaftslehre als Handschrift für seine Zuhörer, Leipzig: bei Christian Ernst Gabler, 1794, pp. 246-247 (tradução de Diogo Ferrer, Lisboa: Edições Colibri, 1997). No entanto, Cornforth não aprofunda a sua crítica em qualquer um destes sentidos.

20 "Ele [Dewey] confundiu o objeto de conhecimento, o objeto que nós sabemos - que existe independentemente do nosso conhecimento -, com o relato que somos capazes de dar dele, em termos dos aspetos particulares dele que temos sido capazes de investigar." - "He [Dewey] has confused the object of knowledge, the object which we know - which exists independently of our knowing it - with the account we are able to give of it in terms of the particular aspects of it which we have been able to investigate.", sublinhado do autor, Cornforth, In Defense of Philosophy, p. 184. 
jeito e objeto ${ }^{21}$ : por muitas voltas que dê, no final das contas, pouco parece diferir de um idealismo que afirme despudoradamente um sujeito (por exemplo, Deus) como anterior ao ser ou que nada existe fora da esfera da consciência.

Vejamos ainda, o Pragmatismo considera a sensação, a experiência, como uma divisória que separa a consciência do mundo exterior (não há unidade real), e a sensação é a única coisa sobre a qual podemos ter verdadeiramente conhecimento, em vez de uma ligação da consciência ao mundo, de uma imagem (Abbild) deste ${ }^{22}$.

O Pragmatismo abstrai da realidade o caráter relativo do conhecimento humano e faz de tal abstração a sua verdadeira máxima ${ }^{23}$. Ignora, por completo, a questão da dialética, mais ainda a da dialética do absolu-

21 Vejamos: "A ideia fundamental do idealismo posterior a Kant e inspirando-se em Kant é, ao que ele [Sérgio] nos diz, a da insuperável correlatividade do sujeito e do objeto.”, Magalhães-Vilhena, António Sérgio. O Idealismo Crítico e a Crise da Ideologia Burguesa, p. 62. Este foi um dos problemas herdados do idealismo alemão - cisão entre sujeito e objeto -, pretensamente resolvido por Georg W. F. Hegel (1770-1831), porém, ainda em supostos idealistas: sujeito e objeto identificavam-se. Marx elabora de uma certa maneira uma resposta à questão da antinomia entre a teoria e a prática (cf. MagalhãesVilhena, "Ideia e Matéria. A Teoria, Força Material", in id. Antigos e Modernos. Estudos de História Social das Ideias, Lisboa: Livros Horizonte, 1984, pp. 265-266). Este autor alemão recusou a identidade defendida por Hegel, por exemplo: "[...] num idealismo em que se afirma a unidade absoluta, a identidade da consciência e do ser, do espírito e da natureza, não há lugar para o reflexo [Spiegebild] do ser pela consciência.", Magalhães-Vilhena, "Ideia e Matéria. A Teoria, Força Material", p. 267. Em Marx, a relação sujeito-objeto, a partir de uma noção como a de reflexo, é sinal de unidade e não de identidade. O sujeito tem, assim, do que é a realidade, porque não a espelha ou com ela se identifica, um conhecimento aproximado do que é o objeto. Cf. Vladimir Lénine, Materialismo e Empiriocriticismo. Notas Críticas sobre uma Filosofia Reaccionária, Lisboa-Moscovo: Edições “Avante!"-Edições Progresso, 1982, p. 75 n. Na gnosiologia marxista, e com maior evidência na sua ontologia, em última instância, não há lugar para a cisão ou correlação (relação de equivalência) entre o sujeito e o objeto.

22 Cf. Lénine, Materialismo e Empiriocriticismo, pp. 38-39. Nesse mesmo sentido, o Pragmatismo confirma a sua herança mecanicista, uma vez que pode apelar a um estímulo "extraorgânico" como clique "intraorgânico", ora, como se de um "motor" se tratasse, pronto a dar uma resposta adequada a um estímulo direto. Cf. Cornforth, In Defense of Philosophy, p. 167.

23 Por exemplo, nas palavras dos próprios: "Dizemos que esta teoria [uma nova teoria] resolve-o globalmente de forma mais satisfatória do que aquela teoria; mas não mais do que satisfatoriamente para nós mesmos, e cada indivíduo enfatizará diferentemente os seus pontos de satisfação. Portanto, num certo grau, tudo é plástico neste caso." - "We say this theory solves it on the whole more satisfactorily than that theory; but that no more satisfactorily to ourselves, and individuals will emphasize their points of satisfaction differently. To a certain degree, therefore, everything here is plastic.", James, Pragmatism, p. 61. 
to (a realidade exterior, também relativa pelo seu devir) e do relativo (a possibilidade de conhecimento condicionada historicamente, mas também absoluta no seu acerto com a objetividade) $)^{24}$.

Desta maneira, o Pragmatismo acaba por inflacionar o lado voluntário e subjetivo da atividade humana e minimiza o facto de que as iniciativas da ação humana são invocadas, circunscritas e decididas pelas condições objetivas da vida ${ }^{25}$. As quais compete investigar e compreender como se regem (e se, e como, podem ser transformadas), será isto "o sentido mesmo da progressão da ciência" que Magalhães-Vilhena encontrava traduzido

24 Nas palavras de Lénine: "Ser materialista significa reconhecer a verdade objetiva que nos é revelada pelos órgãos dos sentidos. Reconhecer a verdade objetiva, isto é, não depende do homem e da humanidade, significa reconhecer de uma maneira ou doutra, a verdade absoluta. [...] Para fazer avançar o materialismo, é preciso acabar com esse jogo banal com as palavras 'verdade eterna', é preciso saber colocar e resolver dialeticamente a questão da correlação entre a verdade absoluta e a verdade relativa. [...] o pensamento humano é, pela sua natureza, capaz de nos dar, e dá, a verdade absoluta, que se compõe da soma de verdades relativas. Cada degrau no desenvolvimento da ciência acrescenta novos grãos a esta soma de verdade absoluta, mas os limites da verdade de cada tese científica são relativos, sendo ora alargados ora restringidos à medida que cresce o conhecimento.", Lénine, Materialismo e Empiriocriticismo, pp. 100-101 - "To be a materialist is to acknowledge objective truth, which is revealed to us by our sense-organs. To acknowledge objective truth, i.e., truth not dependent upon man and mankind, is, in one way or another, to recognize absolute truth. [...] If we want to advance materialism, we must drop this trivial play with the words 'eternal truth'; we must learn to put, and answer, the question of the relation between absolute and relative truth dialectically. [...] Human thought then by its nature is capable of giving, and does give, absolute truth, which is compounded of a sum-total of relative truths. Each step in the development of science adds new grains to the sum of absolute truth, but the limits of the truth of each scientific proposition are relative, now expanding, now shrinking with the growth of knowledge." Como não temos conhecimento de russo, optámos por colocar uma outra tradução da obra de Lénine para comparação com a tradução portuguesa utilizada, cf. tradução de Abraham Fineberg, in Clemens Dutt (ed.), Lenin Collected Works, vol. 14, Moscow: Progress Publishers, 1962.

25 Cf. Novack, Pragmatism versus Marxism, p. 196. Com o intuito de dar um exemplo sob a responsabilidade de uma das coordenações do próprio Magalhães-Vilhena, atente-se: "Os pragmatistas consideraram-na [a prática] como a sua esfera única e exclusiva de reflexão filosófica. Descreveram-na como o meio da vida ativa do homem, mas subjetivaram-na, tratando-a como a 'aventura' da consciência na esfera da experiência individual.", Ígor S. Narski, "A Categoria da Práxis e a "Marxologia", tradução do inglês de Jorge Correia Jesuino, in Magalhães-Vilhena (coord.), Práxis. A Categoria Materialista de Prática Social, Lisboa: Livros Horizonte, 1980, vol. 2, p. 111. Apesar de não ser possível confrontar com o excerto original ou comparar com outra tradução, é-nos possível indicar a localização do texto original: Filosófskie Naúki (Ciências Filosóficas), n. ${ }^{\circ}$ 1, 1975, pp. 57-66. 
em Cornforth e que não pode ser compatibilizado com qualquer tipo de idealismo ${ }^{26}$.

Finalmente, quanto às repercussões políticas, com alguma facilidade se percebe por que motivo volta e meia algum político comprometido com as políticas dominantes apela a que "sejamos pragmáticos".

Se, em âmbito pragmatista, se tem de procurar realizar o que parece vir a resultar, conceber alguma coisa que possa lograr efeitos "concebivelmente práticos", e tudo isso se encontrar devidamente "casado" com as experiências anteriores, então, aquilo que se deve procurar realizar não será mais do que uma adequação ao vigente ${ }^{27}$.

26 No entanto, como dito, a prática não pode nunca confirmar por completo a representação humana, podemo-nos aproximar da verdade absoluta, sem nunca a esgotar, mas não por esta ser incognoscível: "[...] o materialismo dialético insiste no caráter aproximativo, relativo, de qualquer proposição científica sobre a estrutura da matéria e as suas propriedades, na ausência de fronteiras absolutas na natureza, na transformação da matéria em movimento de um estado para outro que, do nosso ponto de vista, parece incompatível com o anterior, etc.”, Lénine, Materialismo e Empiriocriticismo, p. 198 - “[...] dialectical materialism insists on the approximate, relative character of every scientific theory of the structure of matter and its properties; it insists on the absence of absolute boundaries in nature, on the transformation of moving matter from one state into another, that from our point of view is apparently irreconcilable with it, and so forth.". A matéria (em movimento) é o primário e o pensamento, a consciência, a sensação, são produto de um desenvolvimento muito elevado (cf. Lénine, Materialismo e Empiriocriticismo, pp. 56-57). A "sensação" é uma propriedade da matéria em movimento. Movendo-se, a matéria produz a sensação (desenvolve os nossos sentidos, isto é, a experiência tal como a entendemos não existiu sempre, antes, sentidos, sensação e experiência são produto da evolução material). A questão é que o refletido é sempre independente do que aquilo que o reflete, do que aquilo que o sente. No fundamental, está em causa a cognoscibilidade da realidade "além" da consciência, da experiência. Se esta cognoscibilidade não fosse possível, se o conhecimento humano não se aproximasse, sem esgotar, da realidade objetiva, porventura, ainda hoje se considerasse de grande "acerto" a "teoria ptolemaica". Dado o exposto do Pragmatismo, seria caso para perguntar: acaso a "teoria ptolemaica" foi verdadeira alguma vez, visto que no seu tempo parece ter "resultado" com bastante "sucesso"? (cf. Novack, Pragmatism versus Marxism, p. 112).

27 Por exemplo, Sid Okun (1912-1986) assinalava: "Na base de Dewey podemos argumentar - e Dewey fá-lo - que o comunismo nunca foi testado e nunca foi experienciado; por conseguinte, não é corrigido, pelo menos, não é corrigido ainda. O capitalismo, por outro lado, "com todas as suas imperfeições" tem funcionado, foi testado no cadinho da história. É uma melhoria definitiva sobre o sistema que o precedeu - o Feudalismo. Com base nos "testes" mecânicos de Dewey a conclusão é inevitável - nós devemos remendar o capitalismo, em vez de avançar para o comunismo." - "On Dewey's basis we may argue - and Dewey does - that Communism has never been tested and has never been experienced; therefore, it is not corrected, at least not correct yet. Capitalism, on the other hand, "with all its imperfections" has worked, has been tested in the crucible 
No essencial, tratar-se-á de um apelo a "fazer o que se tem a fazer", desmente não se afaste muito do que "têm sido" as experiências mais comuns. O Pragmatismo, assim, constituirá politicamente uma teoria de adequação prática às ideias dominantes, sempre de um ponto de vista subjetivista e irracionalista, como Cornforth evidenciava.

\section{§ 3. À guisa conclusiva: o (neo)positivismo e o "meio caminho"}

Chegados aqui, não será demais destacar que a crítica marxista, se se quiser como crítica consequente a todo o Pragmatismo (independentemente das suas miríades orientações), não se pode desligar da crítica (marxista também) a todo o positivismo, mas também neopositivismo, em geral ${ }^{28}$.

Na verdade, o Pragmatismo apenas se distingue do positivismo em geral, na medida em que interpreta as ideias, essencialmente, como "regras para a ação", ao passo que o positivismo interpreta as ideias como "regras de predição e organização das sensações" (rules for predicting the order of sensations ${ }^{29}$ ).

of history. It is a definitive improvement over the system that preceded it - Feudalism. On the basis of Dewey's mechanical "tests" the conclusion is inescapable - we must patch up Capitalism, rather than go over to Communism.", Sidney Okun, John Dewey. A Marxian Critique, Chicago, Illinois: Revolutionary Workers, League U.S., 1942, pp. 7-8.

28 "Lénine [autor que inspirou o nosso homenageado, como, igualmente, inspirou Cornforth,] indicava como o pragmatismo, em última análise, procede das mesmas premissas subjetivistas e chega às mesmas conclusões antimaterialistas que o positivismo." "Lenin indicates how pragmatism in the last analysis proceeds from the same subjectivist premises and arrives at the same antimaterialist conclusions as positivism.”, Novack, Pragmatism versus Marxism, p. 273. Nas suas próprias palavras: "Talvez a 'última moda' da filosofia americana mais recente seja o 'pragmatismo' (do grego pragma, ato, ação; filosofia de ação). É talvez do pragmatismo que as revistas filosóficas falam mais. O pragmatismo ridiculariza a metafísica tanto do materialismo como do idealismo, exalta a experiência e só a experiência, reconhece a prática como único critério, invoca a corrente positivista em geral [...].”, Lénine, Materialismo e Empiriocriticismo, p. 258 n. - "Perhaps the 'latest fashion' in the latest American philosophy is 'pragmatism' (from the Greek word "pragma" - action; that is, a philosophy of action). The philosophical journals speak perhaps more of pragmatism than of anything else. Pragmatism ridicules the metaphysics both of materialism and idealism, acclaims experience and only experience, recognises practice as the only criterion, refers to the positivist movement in general $[\ldots] "$.

29 Cornforth, In Defense of Philosophy, pp. 159-160, 161. Salvo as diferenças de primeiro impacto: "O positivismo e o pragmatismo intersetam-se um com o outro em tantos pontos que às vezes é difícil traçar uma linha entre eles. Tal acontece porque representam duas variedades de uma posição filosófica essencialmente idêntica, refletindo diferentes 
É uma determinada maneira de entender a prática que os distingue prima facie e o que convoca o Pragmatismo a uma (aparentemente) preferencial crítica marxista, uma vez que a prática também tem no marxismo um lugar central, porém, distinto.

Não obstante, o Pragmatismo, tal como o positivismo e uma série de outras formulações contemporâneas, prosseguem um caminho de "meio-termo", isto é, de "terceira via" ou como Magalhães-Vilhena assinalava como "feliz expressão" de Cornforth: uma "half-way school"30.

A "terceira via" aparece onde se encontra a recusa em tomar posição (ou partido) pela primazia do sujeito ou do objeto, da teoria ou da prática, da ideia ou da matéria, etc., e se proponha quase sempre uma conciliação entre as partes. Mas atenção tomar partido pela primazia de um, não implica que o outro seja um "simples" derivado daquele. Ou mais politicamente, a "terceira via" aparece na recusa de se tomar partido pela esquerda ou pela direita, embora na verdade acabe por tomá-lo (e creio que todos os presentes imaginam para que lado o toma mais habitualmente...) e também aqui proponha uma conciliação (por exemplo, entre as classes).

Adiante, Magalhães-Vilhena aludia a este half-way, a propósito da pequena-burguesia, certamente pela sua condição social: "entalados" entre o proletariado, iminentemente revolucionário, e os capitalistas, iminentemente monopolistas e reacionários (serve ter presente que em âmbito marxista, mais do que para a generalidade das conceções, as ideias não surgem sem ligação ao desenvolvimento social).

Aqui se encontrará, porventura, o que é mais caraterístico numa crítica marxista, não apenas um confronto de ideias, mas o confronto com o próprio "solo de onde estas brotam" 31 . A um dado passo, precisamen-

interesses vocacionais da mesma ampla camada da classe média na sociedade burguesa. De um ponto de partida ideológico e de base social comum, os positivistas e pragmatistas podem ramificar-se em diferentes domínios e tomar diferentes caminhos de desenvolvimento. Mas eles caminham na mesma direção e mais cedo ou mais tarde vão dar as mãos no seu destino comum." - "Positivism and pragmatism intersect with one another at so many points that it is sometimes difficult to draw a line between them. That is because they represent two varieties of an essentially identical philosophical position, reflecting different vocational interests of the same broad middle-class stratum in bourgeois society. From a common ideological starting point and social foundation, the positivists and pragmatists may branch off into different domains and take differing paths of development. But they are headed in the same direction and sooner or later clasp hands at their common destination.", Novack, Pragmatism versus Marxism, p. 64.

30 Cf. Magalhães-Vilhena, António Sérgio - O Idealismo Crítico: Génese e Estrutura, p. 328.

31 Por exemplo, para Novack o Pragmatismo seria a filosofia por excelência da classe média norte-americana, cf. Novack, Pragmatism versus Marxism, p. 276. 
te uma das vezes em que o nosso homenageado remete para Cornforth, confirmava:

Como provável é também que [o pequeno-burguês] não entenda que a tentativa, anos depois [da moda bergsoniana], de propagandear entre nós o neopositivismo: filosofia anti-metafísica e de tom "científico", mas de facto filosofia da "terceira via", da conciliação camuflada, acobertada, do idealismo e do materialismo em benefício do primeiro, e não já abertamente idealista subjetivista e irracionalista como o bergsonismo - corresponde objetivamente, com a sua problemática e as suas soluções, a uma fase diferente da crise ideológica da burguesia $[\ldots]^{32}$.

Posto isto, e mesmo que apenas por algumas referências episódicas, é caso para dizer que o nosso homenageado fez valer a revisitação dos seus textos.

E mesmo para finalizar, (uma vez que esta mesa é anunciada como "Ideologia e Marxismo") enfatizava ainda que a crítica marxista deve procurar identificar e expor os traços comuns a todas as teorias, ideologias, que pretendam sustentar a incognoscibilidade da realidade (seja mais "à anglo-saxónica” ou mais “à kantiana”), uma vez que estas iludem as leis (gerais) objetivas, mesmo as do movimento natural, mas, mais precisamente, as do movimento social, subjetivizando e relativizando qualquer possibilidade de conhecimento e de transformação da realidade. Bem como a crítica marxista deve compreender e relacionar as referidas teorias com o "solo de onde brotam", o mesmo solo que é a base das diferentes crises ideológicas.

32 Magalhães-Vilhena, António Sérgio. O Idealismo Crítico e a Crise da Ideologia Burguesa, pp. 118-119. Claramente transcende os propósitos da presente comunicação a questão do "bergsonismo" e, em certo sentido, até do próprio neopositivismo. Qualquer reflexão mais detalhada acerca dos mesmos terá de ficar para outra oportunidade. 


\title{
RESUMO
}

O presente texto, mais do que tomar como objeto a bibliografia e/ou biografia de Vasco de Magalhães-Vilhena ou apresentar sucintamente um tema ou temas que o cativaram, pretende, antes, servir-se de uma ou outra referência episódica dos seus textos. Para o caso, pretende servir-se das referências que remetem, como o título anuncia, para a crítica marxista ao Pragmatismo. Crítica que o homenageado não terá desenvolvido, porém, assinalou. Maurice Cornforth é o autor para o qual Magalhães-Vilhena remete o essencial da crítica ao Pragmatismo. Para o efeito, parte-se da conhecida máxima do Pragmatismo acompanhando algumas das suas repercussões (gnosiológicas, ontológicas e políticas) com base na reflexão deste autor britânico.

Palavras-chave: Gnosiologia - Marxismo - Ontologia - Política - Pragmatismo.

\begin{abstract}
The present text, rather than taking as its object the bibliography and/or biography of Vasco de Magalhães-Vilhena or presenting succinctly a theme or themes that captivated him, intends instead to use one or another episodic reference of his texts. In this case, it intends to use the references that refer, as the title announces, to the Marxist critique of Pragmatism. Criticism that the honoree will not have developed, however, he pointed out. Maurice Cornforth is the author for whom Magalhães-Vilhena refers the essentials of criticism to Pragmatism. To this end, it starts from the well-known maxim of Pragmatism accompanying some of its repercussions (gnosiological, ontological and political) based on the reflection of this British author.
\end{abstract}

Key-words: Gnosiology - Marxism - Ontology - Politics - Pragmatism. 